\title{
Laparoscopic management of ileal endometriosis: presented as sub-acute intestinal obstruction
}

\author{
Kavitha Duraisamy Yogini $^{1 *}$, Kalyana S. Kumari ${ }^{1}$, Sathiya R. Murthy ${ }^{2}$
}

\author{
${ }^{1}$ Department of Endogynecology, GEM Hospital and Research Centre, Coimbatore, Tamil Nadu, India \\ ${ }^{2}$ Department of Surgical Gastroenterology, GEM Hospital and Research Centre, Coimbatore, Tamil Nadu, India
}

Received: 19 February 2015

Accepted: 01 March 2015

\section{*Correspondence: \\ Dr. Kavitha Duraisamy Yogini, \\ E-mail: yoginianandvij@ rediffmail.com}

Copyright: $\odot$ the author(s), publisher and licensee Medip Academy. This is an open-access article distributed under the terms of the Creative Commons Attribution Non-Commercial License, which permits unrestricted non-commercial use, distribution, and reproduction in any medium, provided the original work is properly cited.

\begin{abstract}
Patients with bowel endometriosis will usually experience a long delay in getting diagnosed as the physician will always think of other medical conditions related to bowel before considering the possibility of endometriosis. Imaging studies are not sensitive enough for definite diagnosis. Bowel endometriosis can be treated by either hormone therapy or surgical therapy. Surgery should be considered in selected patients, who have severe stenosis of intestinal lumen resulting in obstruction. Small bowel endometriosis may not be accompanied by pelvic endometriosis. When the disease involves the jejunum or the ileum, it usually has a benign course, but in rare circumstances may present as an acute abdomen. Ileal endometriosis should be carefully considered in the differential diagnosis of Crohn's disease, because bowel endometriosis frequently produces local inflammation, adhesions, stricture and angulation. A segmental bowel resection may be required to completely treat their disease. The role of postoperative administration of gonadotropin releasing hormone analogues $(\mathrm{GnRH})$ to prevent disease recurrence or increase symptom free interval is not well established.
\end{abstract}

Keywords: Laparoscopic management, Ileal endometriosis, Crohn's disease, GnRH

\section{INTRODUCTION}

Endometriosis is defined as the presence of endometrial glands and stroma abnormally implanted in locations other than uterine cavity. Depending on the area identified, endometriosis is characterized as endopelvic or extrapelvic. ${ }^{1}$

Extrapelvic endometriosis preferentially involves bladder and bowel. Bowel endometriosis affects between 3.8\% and $37 \%$ of women with endometriosis. The term bowel endometriosis is used when endometrial glands and stroma infiltrates the intestinal wall reaching at least the subserous fat tissue and subserous part of the enteric plexus. The most frequent site of bowel endometriosis is rectum followed by sigmoid colon, ileum, appendix and caecum. Involvement of bowel usually occurs in deep infiltrating endometriosis. Bowel endometriotic lesions may have variable size and depth of infiltration in the bowel wall and therefore cause a wide range of symptoms. In general, small endometriotic lesions reaching only the subserosal fat tissue do not cause symptoms. Larger nodules were infiltrating the intestinal muscular layer cause a wide range of symptoms including dyschezia, constipation, diarrhea, abdominal bloating, painful bowel movements, passage of mucus in stools and cyclical rectal bleeding and rarely extensive fibrosis causing stenosis of bowel lumen resulting in mechanical obstruction. Bowel endometriosis is one of the misdiagnosed form of endometriosis as many of the symptoms are nearly identical to those of several other conditions including acute appendicitis, inflammatory bowel disease, irritable bowel syndrome. ${ }^{2,3}$ 


\section{CASE REPORT}

A case of 37 year old nulligravida with primary infertility admitted with complaints of intermittent lower abdominal pain since 1 year, more since 1 week associated with vomiting and abdominal bloating. She gives h/o frequent hospitalization for similar complaints in past 1 year. Her menstrual cycles were regular except for occasional mild dysmenorrhea. She got evaluated elsewhere. Colonoscopy showed areas of patchy infiltration throughout colon, biopsy suggestive of nonspecific colitis. Diagnostic laparoscopy done 3 months back showed strictures in terminal ileum with minimal free fluid. Biopsy suggestive of fibrovascular tissue. She was suspected to have Crohn's ileitis and started on drugs, but no response.

On examination, she was poorly built and nourished with BMI 17. Her vitals were stable with PR - 90/min, BP 100/70 mmHg. P/A; soft, minimal tenderness in RIF. CT showed dilated small bowel loops with acute bend and luminal narrowing in the zone of transition in the distal ileal loop - probably due to adhesions/bands. On laparoscopy, small bowel loops were distended with stricture one foot away from ileo-caecal junction. Pelvis and other organs grossly were normal. Laparoscopic ileal resection and end to end anastomosis were done. HPE showed resected ileal segment with transmural endometriosis and margins viable. Retrospective analysis of her investigations done during infertility workup did not showed an established diagnosis of endometriosis but during diagnostic hysterolap done in 2010 as part of infertility work up, she had removal of small $2 \mathrm{~cm}$ fundal fibroid and left ovary was hidden behind adhesions, which was released. CA-125 which is a prognostic marker for endometriosis was done postoperatively and found to be elevated $(51.9 \mu / \mathrm{ml})$. She was advised to take 3 doses of $\mathrm{GnRH}$ analogues $3.75 \mathrm{mg}$ once monthly to prevent disease recurrence/increase disease free interval.

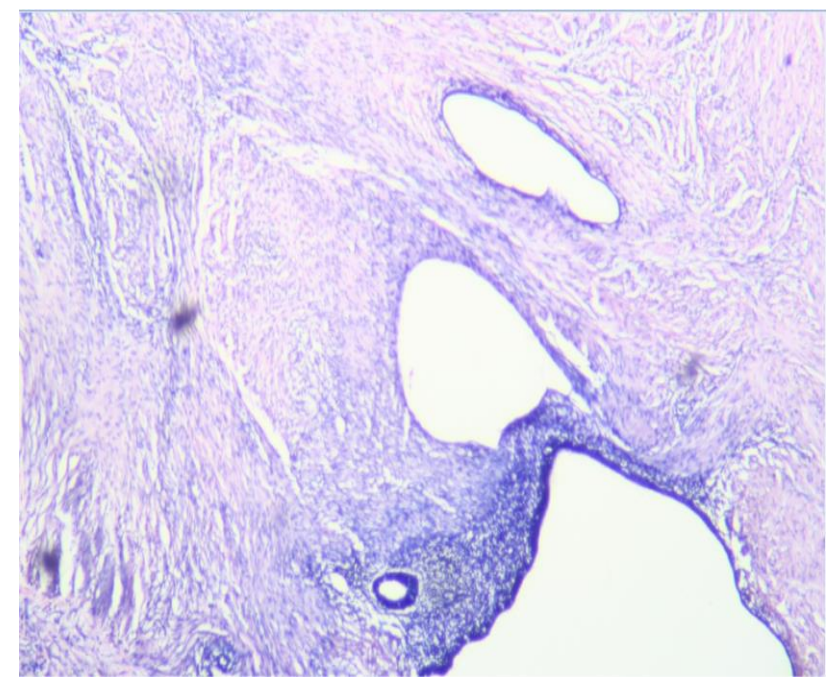

Figure 1: Wall of ileum showing islands of entrapped endometrial glands \& stroma (High power view).

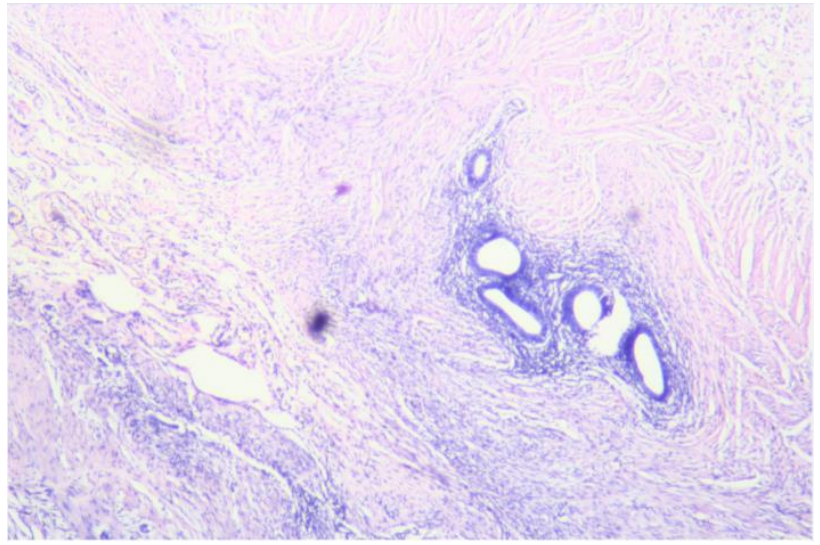

Figure 2: Wall of ileum showing islands of entrapped endometrial glands \& stroma (Low power view).

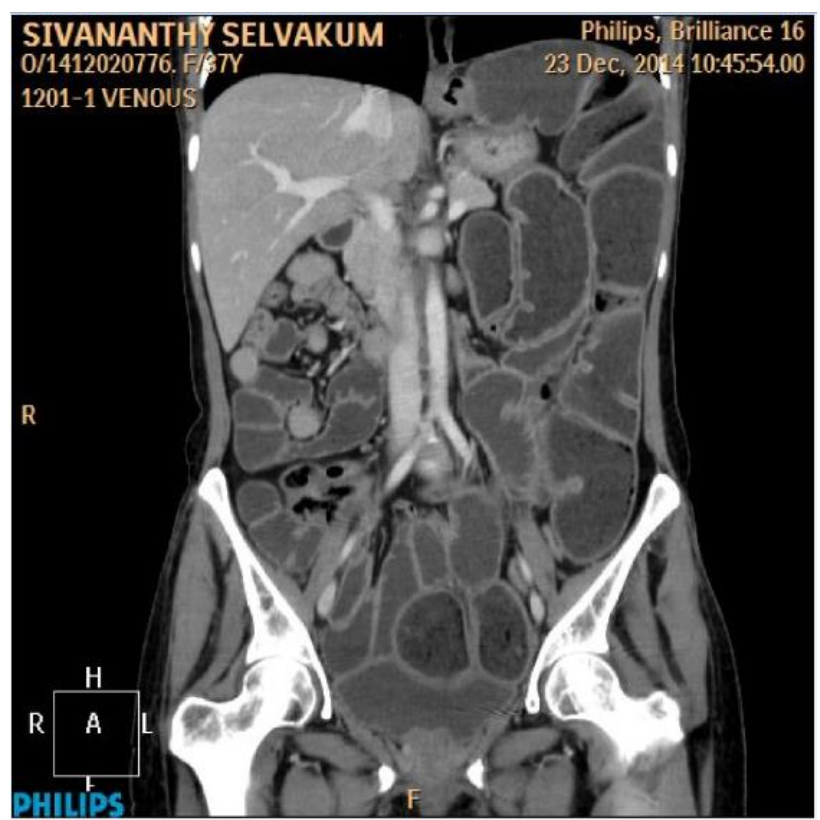

Figure 3: CT scan showing dilated small bowel loops.

\section{DISCUSSION}

The diagnosis of bowel endometriosis is considered in any premenopausal woman who complaints of gastrointestinal symptoms, especially when there are cyclical symptoms and a history of endometriosis. However in most cases it is a retrospective diagnosis following histopathological confirmation of biopsy or resected bowel segment in case of stricture. Imaging studies such as CT and MRI are not sensitive enough for definitive diagnosis. ${ }^{4}$ Colonoscopic biopsy rarely yields the diagnosis, since the endometriosis is usually located subserosally.

For treatment of bowel endometriosis, either surgical therapy or hormone therapy could be chosen according to age, severity of symptoms, infertility, desire for childbearing and the degree of intestinal obstruction. ${ }^{5}$ Hormone therapy alone cannot reverse stricture in the bowel and surgery is indicated in symptomatic disease. In 
acute or sub-acute intestinal obstruction, the mechanical blockage requires urgent surgical intervention. Surgical resection of the moderately to severely obstructed endometriotic bowel has been shown in a study to be safe and to provide long term symptomatic relief.,

When the small bowel is affected, endometriosis has a propensity to develop in the distal ileum, which may lead to fibrosis and stricture formation that can be confused with Crohn's disease. Ileal endometriosis must be considered in the differential diagnosis of Crohn's disease of ileum, even in the presence of Crohn's disease elsewhere in the gastrointestinal tract. Ileal endometriosis should be carefully considered in the differential diagnosis of Crohn's disease in menstruating females who are nulliparous and have dysmenorrhea, dyspareunia, dyschezia and menorrhagia.,

Some studies suggested that the post-surgical administration of gonadotropin releasing hormone analogues is effective in increasing the disease free interval and decreased symptom recurrence rates in patients following surgery with severe endometriosis. ${ }^{10}$ It is difficult to make a definite diagnosis of bowel endometriosis especially when there is no past history of pelvic endometriosis. ${ }^{11}$ So it is most often diagnosed following histopathological confirmation. Laparoscopy should be used for the diagnosis of bowel endometriosis and may be considered for treatment by skilled surgeons.

Funding: No funding sources

Conflict of interest: None declared

Ethical approval: Not required

\section{REFERENCES}

1. Remorgida V, Ferrero S, Fulcheri E, Ragni N, Martin DC. Bowel endometriosis: presentation, diagnosis, and treatment. Obstet Gynecol Surv. 2007;62:461-70.

2. Ferrero S, Camerini G, Ragni N, Remorgida V. Endometriosis and irritable bowel syndrome: comorbidity or misdiagnosis? BJOG. 2009;116:129-30.

3. Machairiotis N, Stylianiki A, Dryllis G, Zarogoulidis $\mathrm{P}$, Kouroutou P, Tsiamis N, et al. Extrapelvic endometriosis: a rare entity or an u derdiagnosed condition? Diagn Pathol. 2013 Dec2;8:194.

4. Bazot M, Lafont $C$, Rouzier R, Rose UG, Thomassin-Naggara I, Darai E. Diagnostic accuracy of physical examination, transvaginal sonography, rectal endoscopic sonography, and magnetic resonance imaging to diagnose deep infiltrating endometriosis. Fertil Steril. 2009;92:1825-33.

5. Simon Ferrero, Giovanni Camerini, Umberto Leone, Roberti Maggiore, Pier L. Venturini, Ennio Biscaldi, et al. Bowel endometriosis: recent insights and unsolved problems. World J Gastrointest Surg. 2011 Mar;3(3):31-8.

6. Cameron IC, Rogers S, Collins MC, Reed MWR. Intestinal endometriosis: presentation, investigation, and surgical management. Int $\mathrm{J}$ Colorectal Dis. 1995;10:83-6.

7. Christopher Whelton, Amab Bhowmick. Acute endometrial bowel obstruction: a rare indication for colonic stenting. Int J Surg Case Rep. 2013;4(2):1603 .

8. Boulton R, Chawla MH, Poole S, Hodgson HJ, Barrison IG. Ileal endometriosis masquerading as crohn's ileitis. J Clin Gastroenterol. 1997 Jul;25(1):338-42.

9. Capell MS, Freidman D, Mikhail N. Endometriosis of the terminal ileum simulating the clinical, roentgenographic, and surgical findings in Crohn's disease. Am J Gastroenterol. 1991 Aug;86(8):105762.

10. Yu-Hung Lin, Li-Jen Kuo, Ai-Ying chuang, Tsun-I Cheng, Chi-Feng Hung. Extrapelvic endometriosis complicated with colonic obstruction. J Chin Med Assoc. 2006;69:47-50.

11. Porpora MG, Pallante D, Ferro A, Crobu M, Cerenzia P, Panici PL. Intestinal endometriosis without evident pelvic foci treated with gonadotropin-releasing hormone agonist. Eur J Obstet Gynecol Reprod Biol. 2006;125:265-6.

DOI: $10.5455 / 2320-1770 . i j r \operatorname{cog} 20150453$

Cite this article as: Yogini KD, Kumari KS, Murthy

SR. Laparoscopic management of ileal endometriosis: presented as sub-acute intestinal obstruction. Int J Reprod Contracept Obstet Gynecol 2015;4:521-3. 